\title{
Teoria e prática no processo de formação inicial de professores de geografia e história ${ }^{1}$
}

Alex Rodrigues da Silva * Poliana da Silva Almeida Santos Camargo**

* Licenciado em Geografia, Universidade Sagrado Coração (USC) . alex.axell@@gmail.com

** Mestre e doutoranda em Educação pela Universidade Estadual de Campinas e professora da Universidade Sagrado Coração (USC). polianasantoscamargo@gmail.com
Resumo: Apresentar aspectos da pesquisa realizada com 40 professores de geografia e história, que atuam no ensino fundamental e médio, em escolas públicas e particulares, é o objetivo deste trabalho. A entrevista é uma atividade prática da disciplina de Psicologia do Desenvolvimento e da Aprendizagem, com a finalidade de articular os conhecimentos produzidos na universidade com aqueles construídos na escola (AZZI; SADALLA, 2002; SISTO; OLIVEIRA; FINI, 2000). Os graduandos de geografia e história entrevistaram os professores, por meio de um questionário, com o intuito de conhecer e analisar como ocorre efetivamente a atuação em suas áreas de conhecimento e quais as contribuições da psicologia para a prática docente. Com base nos dados coletados podemos inferir que o diálogo entre 0 graduando e o professor em exercício é fundamental para subsidiar o processo de formação inicial.

Palavras-chave: Formação de professores. Geografia. História. Prática pedagógica

1 Manifestamos nossos agradecimentos aos graduandos de geografia e história que cursaram a disciplina de Psicologia do Desenvolvimento e da Aprendizagem no primeiro semestre de 2012. 
Para a compreensão do processo de formação dos professores de história e geografia, faz-se necessário apresentar uma breve contextualização do processo histórico da formação dessas duas disciplinas.

A história como disciplina integradora do currículo começou a ser introduzida no Brasil após a independência, entre os anos de 1820 e 1830, recebendo as seguintes denominações: Ensino de História, História Sagrada, História Universal e História da Pátria (FONSECA, 2006, p. 42-43). Nessa época, o ensino da História Sagrada constituía-se como detentor de grande espaço nas escolas mesmo após a ruptura da Igreja com o Estado que aconteceu a partir da Proclamação da Independência do Brasil. A geografia, nesse mesmo período, não era parte constituinte do currículo escolar, servia apenas como suporte para as demais disciplinas, como a leitura, a literatura e até mesmo matemática e física (SILVA, 2010).

Posteriormente, por meio da influência do currículo francês, a geografia começa a figurar entre as matérias escolares, juntamente com a história, as ciências físicas e naturais e as línguas modernas. Assume papel de disciplina secundária, sendo transmitida aos alunos de forma clássica, positivista, descritiva, conteudista e baseada na memorização dos fatos e não da compreensão dos processos, caracterizando-se como algo distante da realidade discente. Nesse contexto, havia falta de um corpo docente formado especificamente para o ensino da geografia (ROCHA, 2000).

É válido ainda ressaltar que o ensino das disciplinas de história e geografia, pós-Independência, serviam ao Estado como incentivadoras ao patriotismo, construtoras da formação da nacionalidade, cabendo à geografia a valorização dos grandes projetos governamentais. Para a história cabia salientar os heróis e marcos históricos, todos como realidades definidas e enraizadas sob o ponto de vista do Estado capitalista, realidade esta que se mantém até grande parte do século XX (OLIVEIRA, 2001; SCHMIDT; CAINELLI, 2004).

Além das dificuldades encontradas pela geografia já citadas e da notória desvalorização, explícita pelo ingresso tardio como disciplina no currículo escolar brasileiro, a geografia possui um agravante em sua história que é chamado de "crise da geografia escolar". Essa crise caracteriza-se pela dificuldade da geografia em firmar seus princípios concernentes à educação, o que acarretava como consequência direta dessa problemática a dificuldade da geografia em justificar seu espaço na qualidade de disciplina nas instituições escolares e, por fim, firmar seus objetivos e princípios pedagógicos (BRABANT, 2001, p. 21). 
Essas dificuldades ocorreram quando a escola passou por mudanças para adequar-se ao novo contexto social que estava emergindo. Segundo Brabant (2001, p. 22), “a geografia faz parte do passivo da velha escola, passivo que é o resultado da transformação das necessidades e referências culturais ideologicamente úteis para a sociedade e da esclerose interna da própria disciplina”.

Contudo, hoje, tanto a história quanto a geografia, após terem passado por um período que se iniciou no final da década de 1970, conhecido como Movimento de Renovação da Geografia, estão sendo trabalhadas, ou deveriam estar sendo trabalhadas, de forma crítica e dinâmica, levando em consideração os conhecimentos que o educando traz consigo, valorizando e destacando a importância do pluralismo cultural e, acima de tudo, buscando a formação integral de cidadãos, de forma consciente e reflexiva, capazes de analisar e compreender o passado e o meio onde vivem para que possam transformar o presente (KOCHHANN; AFONSO, 2009; TADIOTTO; BOGADO; SPANCESKI, 2010; BRASIL, 1998).

Tendo em vista as considerações já citadas neste trabalho e a contextualização histórica das disciplinas de história e geografia, apresentamos a seguir alguns aspectos históricos que marcaram a formação de professores de história e de geografia.

\section{FORMAÇÃO DE PROFESSORES DE HISTÓRIA E GEOGRAFIA}

O início dos cursos de formação de professores de história deu-se na década de 1930, proveniente da fundação das antigas faculdades de Filosofia, Ciências e Letras, onde também a disciplina de geografia, a partir de 1934, passa a ser ministrada nos cursos de formação de professores junto com a disciplina de história, tendo como docentes dessas disciplinas principalmente professores europeus (ROCHA, 2000). Nesse período, pela primeira vez na história de nosso país, dá-se início a uma formação específica e séria, buscando literalmente formar professores de história e geografia para atuarem no antigo $1^{0}$ grau.

Segundo Rocha (2000), no que concerne à geografia, esses profissionais se tornaram fator de mudança em todos os lugares em que apareciam. Tinham uma formação qualificada de fato, sustentada sobre uma concepção científica da geografia aliada simultaneamente a uma pedagogia renovada.

Todavia, as universidades, no início da oferta dos cursos de formação de professores, adotavam um modelo que ficou conhecido como $3+1$, no qual 
os três primeiros anos da graduação se constituíam de disciplinas voltadas para as áreas específicas dos cursos e apenas o último ano era dedicado às disciplinas pedagógicas (PEREIRA, 2006). Esse formato denota que já no início dos cursos de formação de professores havia uma carência em relação ao ensino pedagógico nas universidades, ocasionando uma desarticulação entre as duas áreas do conhecimento, sendo, portanto mais evidenciadas particularidades técnicas/específicas das disciplinas (SAVIANI, 2009).

Com o início do regime militar, houve a tentativa de eliminação da geografia e da história do currículo escolar pela promulgação da Lei noㅗ 5.692/71, que previa a implantação da disciplina de estudos sociais e a gradativa retirada da história e da geografia dos currículos. Segundo Pontuschka, Paganelli e Cacete (2007), essa medida foi de caráter autoritário e tinha como objetivo transformar a história e a geografia em disciplinas inexpressivas no currículo e fragmentar seus devidos conhecimentos.

Outro ponto importante nesse período foi o retrocesso sofrido pelos cursos de geografia e história, por meio da criação da licenciatura curta para atender os alunos de $1^{0}$ grau ( $5^{\underline{a}}$ a $8^{\text {a }}$ séries), que surgiu a partir da Lei $n^{0} 5.692$ em 1971, fornecendo uma formação rápida e generalista com o intuito de suprir a demanda necessária de professores da época, inicialmente em caráter emergencial, porém só foi definitivamente extinta com a Lei de Diretrizes e Bases de 1996 (MENEZES; SANTOS, 2002).

A licenciatura curta, junto com a criação da licenciatura plena nessa época, para atender ao $2^{\circ}$ grau, culminou em uma desestabilização dos elementos estruturais dos cursos e perdas tanto do ponto de vista institucional quanto formativo (SILVA, 2010).

Palma Filho (2004) afirma que nesse período houve sim um empobrecimento dos cursos tanto nos seus conteúdos específicos como pedagógicos, uma vez que a carga horária pedagógica oferecida não era suficiente para garantir uma formação adequada.

Juntamente com a criação das licenciaturas curta e plena, ocorreu nas universidades a separação dos cursos de bacharelado e de formação de professores, que evidencia e reforça a dicotomia entre o saber específico da disciplina/saber pedagógico, formação para a pesquisa/formação para o ensino, conhecimento teórico/conhecimento prático, gerando assim o aumento da distância entre a formação universitária e a realidade da educação escolar básica (FONSECA, 2008). 
Concordamos com Saviani (1996) quando diz que:

[...] um geógrafo, uma vez que tem por objetivo o esclarecimento do fenômeno geográfico, encara a Geografia como fim. Para um professor de Geografia, entretanto, o objetivo é outro: é a promoção do homem, no caso, o aluno. A Geografia é apenas um meio para chegar àquele objetivo. Dessa forma, o conteúdo será selecionado e organizado de modo a se atingir o resultado pretendido. Isto explica porque nem sempre o melhor professor de Geografia é o geógrafo, o que pode ser generalizado nos termos seguintes: nem sempre o melhor professor de determinada ciência é o cientista respectivo (p.50).

É imprescindível, no entanto, ser destacada a relevância do conhecimento científico em sala de aula, articulado com o conhecimento pedagógico, pois como afirmam Azambuja e Callai (2001):

[...] O conhecimento científico, elaborado, é transformado em conteúdo pedagógico e, portanto, em recurso didático necessário à prática social desenvolvida no interior da escola. [...] A ciência do ponto de vista do cientista assume um caráter de fim, já para o educador é encarada como meio (p.188).

De acordo com o exposto, concluímos que a articulação entre o saber científico e o saber pedagógico é fundamental no contexto educacional, principalmente no que se refere à base curricular.

Essa problemática nos dias atuais pode ser facilmente verificada tendo em vista que a manutenção e a ampliação de vagas nos cursos de licenciatura têm sido assumidas por instituições de ensino privadas. As vagas nessas instituições são preenchidas em sua maioria pela classe média que paga por um ensino de qualidade que nem sempre condiz com a necessidade das escolas. Já nas instituições de ensino públicas é notória a priorização das áreas de pesquisa em detrimento das atividades ligadas a licenciaturas, ficando dessa forma o professor com o estigma de profissional de classe média (AZAMBUJA; CALLAI, 2001).

Dessa forma, os cursos de História e Geografia nas faculdades ficaram restritos à pesquisa, mais uma vez evidenciando a desvalorização do processo de formação inicial do aluno graduando para atuar como professor nessas áreas, como afirma Vesentini (2006):

[...] sempre se priorizou a formação do futuro especialista (em Geomorfologia, Geografia Agrária etc.) ou então - especialmente nos anos 1970 e 1980 - a formação do planejador. Mas a carreira docente, com exceção da universitária (considerada normalmente um corolário ou um apêndice da especialização), era e ainda é, em grande parte, vista como algo destinado tão-somente àqueles que não têm competência para exercer outras atividades (p.235). 
Com o fim do regime militar e a redemocratização do país, as duas disciplinas voltam a estruturar o currículo e é iniciado o ensino de uma nova história, que:

[...] interessa-se praticamente por toda a atividade humana, estando preocupada com as pessoas comuns e com as mentalidades coletivas, substitui ou complementa a narrativa com a análise das estruturas e considera como fontes todo o tipo de vestígio deixado pelo homem, além de criticar as fontes oficiais porque expressam o ponto de vista oficial (CRUZ, 1999, p. 73).

Essa nova perspectiva pretendia diferenciar-se da tradicional, que promovia uma visão limitada do conhecimento, criando mentes acríticas e passivas, essencialmente mnemônicas, transmitindo o conhecimento pronto e acabado, não passível de mudança (CRUZ, 1999).

Já a geografia, mesmo após a redemocratização, ainda não conseguiu sanar os problemas de sua crise. Ela ainda é vista como muito decorativa e parecendo não muito interessante aos alunos, pela visão equivocada de não ser atuante na vida destes.

Isso não quer dizer que a Geografia seja assim, que não tenha um papel importante a cumprir na formação das pessoas, ao contrário, quer dizer que o sistema de ensino, a escola, os próprios professores e, inevitavelmente, os alunos não a reconhecem e por isso não se comprometem com o saber geográfico (SILVA, 2010, p. 10).

Com base no resgate histórico realizado, podemos inferir que são notórias a precarização e a desvalorização dos processos para a formação de professores, em que as atividades relacionadas à pesquisa são mais valorizadas. Tendo em vista os processos de formação, objetivamos compreender como os professores que já atuam nas áreas de geografia e história desenvolvem sua prática docente.

\section{Metodologia}

No primeiro semestre de 2012 foi realizada uma pesquisa pelos graduandos dos cursos de Geografia e História de uma universidade particular, localizada em Bauru, SP. A referida investigação era uma das exigências para a conclusão da disciplina de Psicologia do Desenvolvimento da Aprendizagem, com o objetivo de articular os conhecimentos construídos na disciplina com aqueles vivenciados pelos professores que já atuam em escolas particulares e públicas. Os alunos graduandos deveriam entrevistar o docente utilizando 
um roteiro semiestruturado. Os docentes deveriam ser formados nos cursos de Geografia e/ou História e também ministrar as disciplinas geografia e/ou história no ensino fundamental - ciclo Il e ensino médio.

O roteiro utilizado para coleta de dados era composto por itens de identificação do entrevistado e por onze questões: 1) Qual sua renda média mensal?; 2) Por que você decidiu ser professor(a)?; 3) Quais são as dificuldades (da escola, do ensino, suas e dos alunos) que você enfrenta ao lecionar?; 4) Quais são as estratégias que você utiliza para vencer essas dificuldades escolares e de aprendizagem?; 5) Além do conhecimento específico da área (disciplina - conteúdo que leciona), que outros conhecimentos e mecanismos são utilizados na hora de lecionar?; 6) Quais são os referenciais ou teorias que embasam sua metodologia de ensino (teóricos da psicologia ou da didática, tais como Piaget, Vygotsky e outros)? E por que estes são utilizados?; 7) Você tem em sua sala de aula algum(a) aluno(a) com necessidades especiais? Qual a necessidade? Que mecanismos ou estratégias você utiliza para ensinálo(a)?; 8) Para você, o que é ser um bom (boa) professor(a)?; 9) 0 que você mudaria na escola?; 10) Se pudesse mudar de profissão hoje, continuaria sendo professor(a) ou escolheria outra profissão? Justifique sua resposta. e 11) Para você, qual seria a relação entre ensino, aprendizado e afetividade? Justifique sua resposta.

A escolha dos entrevistados ficou a critério dos graduandos, que foram orientados a previamente pedirem autorização para o responsável da instituição de ensino antes de escolherem um professor para a realização da entrevista.

Todos os professores participantes assinaram o termo de consentimento livre e esclarecido, garantindo assim o sigilo em relação aos nomes dos entrevistados e a autorização para que os dados fossem publicados.

A análise dos dados foi realizada utilizando-se a técnica da análise de conteúdo que se divide em três fases: 1) pré-análise, que se caracteriza pela leitura preliminar dos dados, em que deve ser decidido o procedimento de análise; 2) análise do material, em que o mesmo será categorizado tendo em vista a similaridade de respostas e seus números quantificados, e 3) tratamento dos resultados, que se constitui da apuração e interpretação dos dados levantados (BARDIN, 1977; RICHARDSON; PERES; CORREIA; PERES; WANDERLEY, 1989). 
A pesquisa foi realizada com 40 professores de geografia e história, abrangendo as cidades de Agudos, Arealva, Avaí, Bariri, Bauru, Boraceia, Cerqueira César, Duartina, Iacanga, Ibitinga, Igaraçu do Tietê, Itapuí, Itatinga, Lençóis Paulista, Macatuba, Mineiros do Tietê, Reginópolis, São Paulo e Santa Cruz. 0 mais novo trabalha há dois anos e o mais experiente atua há 35 anos no magistério. São do sexo feminino 53\% e do sexo masculino, 47\%. As idades variam de 21 a 66 anos. Dentre os entrevistados, 28 atuam em escolas públicas; sete em escolas particulares e oito nos dois contextos.

Quando questionados sobre por que decidiram ser professores, os motivos mais apontados foram por gosto/vocação $(37,5 \%)$ e a fascinação pelo ensino com anseio de mudar o mundo (17,5\%). Outro aspecto relevante é que $10 \%$ dos entrevistados afirmaram que não iniciaram na licenciatura por gosto; $75 \%$ deles afirmam que continuam na profissão porque hoje gostam do que fazem (Tabela 1).

TABELA 1 - POR QUE DECIDIU SER PROFESSOR(A)?

\begin{tabular}{|c|c|c|}
\hline Motivos & $\begin{array}{l}\text { Frequência das } \\
\text { respostas }\end{array}$ & Porcentagem \\
\hline Influência de familiares & 5 & $12,5 \%$ \\
\hline Gosto/vocação & 15 & $37,5 \%$ \\
\hline Admiração por professores & 5 & $12,5 \%$ \\
\hline Paixão pela disciplina & 3 & $7,5 \%$ \\
\hline $\begin{array}{l}\text { Fascinação pelo ensino/anseio } \\
\text { de mudar o mundo }\end{array}$ & 7 & $17,5 \%$ \\
\hline $\begin{array}{l}\text { Não queria ser professor, } \\
\text { mas as circunstâncias o direcionou } \\
\text { para esta profissão }\end{array}$ & 4 & $10 \%$ \\
\hline Missão pedagógica & 1 & $2,5 \%$ \\
\hline TOTAL & 40 & $100 \%$ \\
\hline
\end{tabular}

Em relação às dificuldades (da escola, do ensino, suas e dos alunos) que os entrevistados enfrentam ao lecionar, 55\% responderam que a maior dificuldade está em superar o desinteresse dos alunos e a falta de perspectiva. Logo em seguida, com 30\% das respostas, são elencadas a falta de disciplina, o desrespeito por parte dos alunos, a falta de material, ou materiais desatualizados e em mau estado. 
A falta de suporte profissional adequado para os alunos, como professores auxiliares para trabalhos com alunos com necessidades especiais, psicólogos, entre outros, também foi citada. A questão da estrutura familiar precária e o desinteresse dos pais aparecem nos dados com $27,5 \%$ como alvo de queixas; $20 \%$ apontam que o sistema educacional é falho e inadequado, com um sistema apostilado fraco; já problemas como a progressão continuada e a superlotação das salas de aula aparecem em apenas 5\%.

Trabalhos realizados com criatividade, dinâmicas em grupo, trabalhos diferenciados com músicas, filmes, jornais, revistas, tecnologia e passeios são citados por $47,5 \%$ dos entrevistados como estratégias utilizadas para vencer essas dificuldades escolares e de aprendizagem, e 30\% apontam ser fundamental trabalhar com a realidade do aluno respeitando suas particularidades.

Questionados sobre quais são os conhecimentos e mecanismos utilizados na hora de lecionar, são citados dinâmicas, trabalho diferenciado com músicas, filmes, jornais, revistas, tecnologia, passeios, entre outros, que aparecem como mecanismos prediletos nessa questão (37,5\%), seguidos da utilização de outras disciplinas (17,5\%), da própria experiência de vida e do uso da psicologia da educação (15\%).

Os dados levantados acerca de quais os referenciais ou teorias que embasam a metodologia de ensino e por que esses são utilizados apresentam números preocupantes, sendo que $84,21 \%$ afirmam usar referenciais teóricos para embasar sua metodologia de ensino, 7,89\% não usam e 7,89\% alegam não funcionarem em sala de aula. Dentre os que afirmaram utilizar alguma referência, somente $68,75 \%$ denominaram os autores que as fundamentam.

Os autores citados como referenciais teóricos, assim como a quantificação de seus percentuais segundo a citação dos entrevistados, podem ser averiguados na Tabela 2.

\section{TABELA 2 - REFERENCIAIS TEÓRICOS}

\begin{tabular}{|c|c|c|}
\hline Teóricos citados & Frequência de respostas & Porcentagem \\
\hline Paulo Freire & 4 & $18,18 \%$ \\
\hline Jean Piaget & 6 & $27,27 \%$ \\
\hline Lev Semenovich Vygotsky & 18 & $81,81 \%$ \\
\hline Karl Max & 1 & $4,54 \%$ \\
\hline Henri Wallon & 1 & $4,54 \%$ \\
\hline Milton Santos & 1 & $4,54 \%$ \\
\hline
\end{tabular}


Visando compreender um pouco sobre como é realizada a inclusão de alunos com necessidades especiais no ensino regular, foi indagado aos entrevistados se possuíam alunos com necessidades especiais em suas salas, quais seriam essas necessidades e que mecanismos ou estratégias eram utilizados para ensiná-los.

Dos entrevistados, 35,89\% afirmaram possuir alunos com algum tipo de necessidade especial, sendo que $21,48 \%$ possuem alunos com déficit de atenção, acompanhados por psicólogo; 21,48\% possuem alunos com surdez profunda, em que o auxílio de outros alunos e a comunicação por Libras é fundamental; e 14,28\% têm em sala alunos com deficiência auditiva menos severa, utilizando ajuda de professor auxiliar quando possível.

Relataram casos de dislexia, realizando a adaptação da avaliação, trabalhos orais e avaliação escrita, $14,28 \%$. Os casos de hiperatividade são citados por $14,28 \%$, que afirmam ser necessária uma metodologia diferenciada, porém não a explicitam; 14,28\% afirmam apenas possuírem alunos com necessidades especiais, mas não citam quais são elas, tampouco a metodologia empregada. Ainda 7,14\%, número que representa um entrevistado, mencionam deficiência intelectual leve, trabalhando com o auxílio de professores especiais, reforços e atividades em dupla; 7,14\% possuem aluno com baixa visão e utilizam provas e apostilas ampliadas e $7,14 \%$ relatam que possuem um aluno com deficiência física e motora e dizem ser necessária mais paciência e atenção.

Outro questionamento realizado foi acerca do que era ser um bom professor na visão dos entrevistados. Diversas foram as qualidades salientadas, porém as mais ressaltadas pelos professores foram: que é exercício de amor ao próximo, dedicação, carinho, gostar do que faz, atualizar-se sempre, auxiliar na formação de um ser humano melhor, transmitir valores, não ter rotina, adaptar-se à diversidade dos alunos, transmitir conhecimento com criticidade, ter domínio do conhecimento específico, conquistar a confiança do aluno, ter um bom relacionamento e empatia com os alunos.

Tratando especificamente sobre o que mudariam na escola, $17,94 \%$ dos entrevistados melhorariam os recursos e a estrutura da escola, englobando sala de informática, biblioteca, livros, contratação de profissionais diversificados, entre outros.

Mudanças no sistema educacional de nosso país foram citadas por apenas 15,38\%, entretanto não defenderam especificamente o que mudariam, passando por diversas questões como a valorização profissional, aumento 
nas verbas para educação e método de ensino, por exemplo. Contudo, para 10,25\%, o que deveria mudaré a forma de se trabalhar com os alunos, aplicação de mais atividades práticas e a prática pedagógica, o que implicaria maior apoio aos professores por parte da direção e coordenação. Não mudariam nada 5,12\%. Mais dados complementares podem ser consultados na Tabela 3.

TABELA 3 - O QUE MUDARIA NA ESCOLA

\section{Mudanças}

Melhoria de recursos e estrutura (sala de informática, biblioteca, livros, profissionais diversificados, etc.)

\begin{tabular}{|c|c|c|}
\hline Mudar o governo/"sistema" & 6 & $15,38 \%$ \\
\hline Forma de se trabalhar com os alunos, mais atividades práticas, prática pedagógica, etc. & 4 & $10,25 \%$ \\
\hline Obrigatoriedade do estudo & 3 & $7,69 \%$ \\
\hline Mentalidade do professor & 3 & $7,69 \%$ \\
\hline Melhores salários & 3 & $7,69 \%$ \\
\hline Progressão continuada & 2 & $5,12 \%$ \\
\hline Melhora na disciplina e organização escolar & 2 & $5,12 \%$ \\
\hline Redução de alunos por sala & 2 & $5,12 \%$ \\
\hline Formação inicial do professor & 2 & $5,12 \%$ \\
\hline Não mudaria & 2 & $5,12 \%$ \\
\hline Forma de lidar com os alunos & 1 & $2,56 \%$ \\
\hline Forma de falar e interagir com os pais & 1 & $2,56 \%$ \\
\hline Melhor preparo dos profissionais da educação & 1 & $2,56 \%$ \\
\hline Salas ambientes & 1 & $2,56 \%$ \\
\hline Maior oferta de formação continuada & 1 & $2,56 \%$ \\
\hline Direção da escola/mais autoridade para o professor & 1 & $2,56 \%$ \\
\hline Mais investimento na educação & 1 & $2,56 \%$ \\
\hline Sistema de apostilas & 1 & $2,56 \%$ \\
\hline Grade horária/mais aulas para a área de humanas & 1 & $2,56 \%$ \\
\hline Sistema de notas & 1 & $2,56 \%$ \\
\hline Maior participação dos pais & 1 & $2,56 \%$ \\
\hline Uma instituição mais compromissada com o ensino e a aprendizagem & 1 & $2,56 \%$ \\
\hline
\end{tabular}


Quando questionados sobre a possibilidade de mudança de profissão, ou se continuariam sendo professores, $82,5 \%$ dos profissionais afirmam que continuariam na docência. Um dado relevante que não poderia passar despercebido é que mesmo dentre os entrevistados que mudariam de profissão, 28,57\% afirmam que gostam de ser professores. Nas tabelas $4 \mathrm{e}$ 5 estão elencados os motivos pela permanência ou desistência dos docentes em relação à profissão.

TABELA 4 - MOTIVOS PARA A PERMANÊNCIA NA DOCÊNCIA

Motivos

$\begin{aligned} & \text { Por que foi a profissão de escolheu, } \\
& \text { gosta do que faz, pela missão e fé }\end{aligned}$
\begin{tabular}{|l|c|c|}
\hline Pela autonomia da profissão & 26 & $6,06 \%$ \\
\hline Resultados positivos são gratificantes & 2 & $6,06 \%$ \\
\hline Gosta do relacionamento com os alunos & 1 & $3,04 \%$ \\
\hline Não respondeu & 2 & $6,06 \%$ \\
\hline TOTAL & & $100 \%$ \\
\hline
\end{tabular}
de respostas

Porcentagem
Frequência

TABela 5 - MOtivos PARA A MUdANÇA DE PROFISSÃO

\begin{tabular}{l|c|c|}
\hline Motivos & $\begin{array}{c}\text { Frequência de } \\
\text { respostas }\end{array}$ & Porcentagem \\
\hline Desvalorização dos professores & 3 & $42,85 \%$ \\
\hline Não sabe & 1 & $14,29 \%$ \\
\hline $\begin{array}{l}\text { Escolha de outra profissão que se } \\
\text { aproxime da disciplina que leciona }\end{array}$ & 2 & $28,57 \%$ \\
\hline Engenharia civil & 1 & $14,29 \%$ \\
\hline TOTAL & & $100 \%$ \\
\hline
\end{tabular}

Aúltima questão da pesquisa objetivou saber qual seria a relação entre ensino, aprendizagem e afetividade para os professores. Nessa questão, a maioria dos entrevistados defendeu que existe uma relação de dependência entre os três eixos (47,22\%); outro grupo frisou que a afetividade é fundamental para o exercício da profissão (27,77\%). Todavia, 19,44\% dos entrevistados não conseguiram justificar com clareza sua postura em relação ao tema, 2,77\% dizem que é necessário o equilíbrio entre ensino, aprendizagem e afetividade, e $2,77 \%$ afirmam que são necessários outros fatores, como respeito e ética. 


\section{DISCUSSÃO DOS RESULTADOS: INTERSECÇÃO ENTRE TEORIA E PRÁTICA}

A investigação dos dados coletados nesta pesquisa contribui de forma significativa para a percepção dos desafios, conflitos e anseios vivenciados pelos entrevistados no exercício da docência e, por sua vez, corrobora com os conhecimentos adquiridos na formação de novos professores, articulando conhecimento teórico e prático. Na busca pela averiguação das possíveis causas dos desafios e conflitos, apontados por esses profissionais da educação, discutiremos alguns pontos a seguir.

Para os entrevistados, ser um bom professor é um exercício de amor ao próximo, dedicação, carinho, gostar do que faz (17,07\%), atualizar-se sempre, auxiliar na formação do ser humano melhor, transmitindo valores, não ter rotina e se adaptar à diversidade do aluno (14,63\%), transmitir conhecimento com criticidade, dominar e socializar adequadamente o conhecimento, conquistar a confiança do aluno, ter bom relacionamento e empatia com o mesmo (12,19\%). Algumas das atitudes citadas são habilidades que constituem um bom professor, segundo pesquisa de Cunha (2005).

Gosto de ensinar e educar. Consigo me realizar no que faço. Gostaria que houvesse um maior reconhecimento por parte dos governos e sociedades com relação ao papel e função do professor (P. 14, 47 anos, ministra aulas de história e geografia no ensino fundamental e médio, em escolas pública e particular).

Temos em vista que $37,5 \%$ dos professores entrevistados optaram pela profissão por gosto/vocação e 17,5\% pela fascinação pelo ensino e o anseio de mudar o mundo.

Quando questionados sobre as dificuldades no ensino, um número expressivo de $55 \%$ dos profissionais apontam os alunos como sendo parte de sua dificuldade, indicando o desinteresse e a falta de perspectiva, e $27,5 \%$ apontam a falta de estrutura familiar e o desinteresse dos pais.

Escolheria outra profissão, embora goste muito de ensinar, porém hoje em dia está muito difícil trabalhar com alunos sem perspectiva alguma de vida, sem o suporte, ou seja, a valorização do professor (P. 38, 46 anos, ministra aulas de história no ensino fundamental e médio, em escola pública).

Apenas $30 \%$ citam a falta de material em mau estado ou desatualizado quando disponível e a falta de suporte profissional diversificado aos alunos, como psicólogos, entre outros, e $20 \%$ mencionam o sistema educacional falho, inadequado, dando como exemplo o sistema apostilado fraco nas escolas estaduais.

Os entrevistados explicitaram o que gostariam de mudar na escola: 17,94\% melhorariam os recursos de modo geral, como biblioteca, sala de informática 
e mais profissionais diversificados; $15,38 \%$ mudariam o sistema educacional, alterando a metodologia de ensino, mais verbas do governo para as escolas e melhor remuneração; somente $10,24 \%$ alterariam a forma de se trabalhar com os alunos, inserindo mais atividades práticas e mudando sua prática pedagógica em si. Uma porção ínfima ressalta problemas provenientes da própria formação profissional, como: mentalidade do professor, formação inicial, melhor preparo dos profissionais da educação e maior oferta de formação continuada (Tabela 5). Com base nos dados coletados, o aluno vem de uma estrutura familiar precária que gera desmotivação no professor; por sua vez, o Estado não dá subsídios necessários para a prática docente, o que maximiza ainda mais a desmotivação do docente.

Entretanto, expondo os métodos e estratégias de ensino utilizados para superar as dificuldades encontradas em sala de aula, 47,5\% mencionam trabalhos diferenciados com mídias, jornais, filmes, revistas, músicas, passeios e trabalhos em grupo, e 30\% citam que é importante trabalhar diretamente com a realidade do aluno.

Quando questionados sobre quais outros conhecimentos seriam importantes além dos específicos de suas disciplinas, 37,5\% tornam a mencionar trabalhos diferenciados e criativos, sendo que somente $17,5 \%$ utilizam trabalhos interdisciplinares e 15\% alegam utilizar a experiência de vida, demonstrando certa carência nesse quesito. São urgentes pesquisas para se compreender intersecções entre aspectos cognitivos e emocionais, como afirmam Leite (2006); Almeida; Mahoney (2011); Martinez; Scoz; Castanho (2012), dentre outros.

Na realidade, a questão teórica é apenas embasada na universidade. Na prática, as teorias pedagógicas não são aplicadas (P. 15, 35 anos, ministra aulas de geografia no ensino fundamental, em escola pública).

Os referenciais e teorias pedagógicas funcionam para concurso, na prática não (P. 4,50 anos, ministra aulas de história no ensino fundamental, em escola pública).

Relacionando os aspectos da falta de profissionais que atuem com a interdisciplinaridade, o fato de 7,89\% afirmarem que referenciais teóricos não funcionam na sala de aula e $68,75 \%$ dos $84,21 \%$ de entrevistados que afirmaram utilizar os referenciais não citarem seus autores, a constatação de que $19,44 \%$ não conseguirem justificar com clareza a relação entre ensino aprendizagem e afetividade, constatando-se um desconhecimento sobre a sutileza e profundidade dessas relações, e que a afetividade está também vinculada a aspectos negativos das interações sociais e cognitivas, somado aos dados referidos anteriormente de que apenas uma porção ínfima 
ressalta problemas provenientes da própria formação profissional quando questionados sobre o que melhorariam na escola.

Com base nos dados coletados, podemos inferir que os professores têm dificuldade em atuar de maneira interdisciplinar e não conseguiram citar quais são os referenciais teóricos utilizados no contexto da sala de aula. Dos entrevistados, 7,89\% afirmaram não utilizar nenhum referencial teórico para embasar suas aulas, enquanto que $68,75 \%$ explicitaram a importância dos referenciais, sem, no entanto, denominá-los.

Constatamos que $19,44 \%$ dos professores não conseguiram justificar com clareza a relação entre ensino, aprendizagem e afetividade, evidenciando um desconhecimento sobre a sutileza e profundidade dessas relações, e que a afetividade está também vinculada a aspectos negativos das interações sociais, cognitivas e emocionais.

Apenas alguns professores ressaltaram problemas provenientes da própria formação profissional quando questionados sobre o que melhorariam na escola.

É urgente e fundamental uma autoanálise por parte dos professores, no que concerne à sua prática pedagógica, uma vez que tais práticas provêm de um novo olhar da educação, o que pode significar, para muitos profissionais, um processo do reaprender sua própria prática pedagógica. No entanto, as práticas interdisciplinares, os estudos sobre afetividade e a pesquisa pedagógica corroboram e são essenciais para o processo ensino-aprendizagem, como defendido por Fazenda (2008); Abreu; Almeida (2008) e Leite (2006).

Sem o aporte adequado do governo, os profissionais se encontram desguarnecidos, trabalhando com classes superlotadas e sem conseguir desempenhar seu papel de educador de forma plena, nem com os alunos que não carecem de atenção especial, quiçá com os que necessitam (VILLELA; GUERREIRO; LOPES, 2011).

Sim, vários. Tento me adaptar à realidade deles, mas o número de alunos na sala de aula atrapalha, é difícil dar atenção a um só com uma grande quantidade de alunos para ensinar, então sempre deixo outro aluno sentado com a menina (que no caso é surda-muda) para poder lhes ajudar nas atividades (P. 41, 46 anos, ministra aulas de geografia no ensino fundamental e médio, em escola pública).

Temos alunos com deficiência mental, nível não compatível com a idade. É difícil porque a atenção deveria ser maior a eles, mas com 38 alunos fica impossível [...] Para mim, a inclusão foi jogá-los na escola pública despreparada, ou seja, uma falsa política (P. 8, 43 anos, ministra aulas de história no ensino médio, em escola pública). 
Portanto, é possível averiguar a necessidade do Estado em subsidiar políticas públicas consistentes sobre a inclusão de alunos com necessidades especiais no ensino regular, sendo que, segundo os próprios entrevistados, na atual conjuntura do ensino público as metas de inclusão não estão sendo alcançadas.

\section{CONSIDERAÇÕES FINAIS}

A investigação da prática pedagógica de professores de geografia e história ainda se trata de um campo vagamente pesquisado, provavelmente por assumir papel secundário na visão de muitos profissionais, em detrimento da matemática e da língua portuguesa, por exemplo (SAMPAIO; VLACH; SAMPAIO, 2009), embora não sejam menos importantes para a formação dos jovens, no que concerne a uma visão crítica do espaço e tempo, constituindo parte do corpo de disciplinas curriculares obrigatórias para o ensino fundamental (BRASIL, 1996, 1998).

Maior atenção voltada às problemáticas enfrentadas pelos professores no exercício da docência é urgente, tendo em vista que um número cada vez menor de jovens opta por campos de atuação na educação (GATTI; GARCIA, 2011). Segundo pesquisa realizada pela Fundação Carlos Chagas, apenas $2 \%$ dos jovens estudantes do ensino médio pretendem seguir carreira em pedagogia ou licenciatura (RATIER; SALLA, 2010).

Os professores necessitam, além de subsídios materiais do governo para suprirem suas necessidades dentro e fora das salas de aula, de condições e estímulos que os incentivem em sua formação continuada, pesquisa e aprimoramento para que possam reaver a autoestima de outrora.

Novas pesquisas e ações, como esta, que aproximem os graduandos de licenciatura da realidade da prática pedagógica também são imprescindíveis para que os discentes tomem consciência de sua escolha, da realidade profissional e se empenhem em busca de novos mecanismos e soluções que contribuam tanto para a sua formação quanto para a melhoria e desenvolvimento do processo de ensino-aprendizagem.

É de nosso desejo que esta pesquisa, assim como contribuiu para o desenvolvimento dos graduandos dos cursos de Geografia e História dessa universidade bauruense, possa corroborar com o exercício pedagógico de nossos pares e auxiliar na elaboração de futuros trabalhos referentes aos temas abordados neste artigo. 


\section{Theory and practice in initial education process of teachers of Geography and History}

Abstract: The purpose of this document is to show aspects of a research made with 40 Geography and History teachers working at junior and senior high school, both in public and private schools. The interview is a practical activity in the Psychology of Development and Learning subject which aims at articulating knowledge produced at the university with those created at school (AZZi: SADALLA, 2002; SISTO; OLIVEIRA; FINI, 2000). Geography and History undergraduates interviewed teachers using a questionnaire, aiming at knowing and analyzing how their actuation in their knowledge areas really occurs and which are psychology's contributions to the teaching practice. Based on collected data we can infer that dialogue between undergraduates and working teachers is essential to assist initial education process.

Keywords: Teacher education. Geography. History. Pedagogical practice. 


\section{REFERÊNCIAS}

ABREU, R. M. A.; ALMEIDA, D. D. M. Refletindo sobre a pesquisa e sua importância na formação e na prática do professor do ensino fundamental. Revista da Faced, v. 14, p. 73-85, 2008.

ALMEIDA, Laurinda Ramalho de; MAHONEY, Abigail Alvarenga (Orgs.). Afetividade e aprendizagem: contribuições de Henri Wallon. 3.ed. São Paulo: Edições Loyola, 2011.

AZAMBUJA, Leonardo Dirceu de; CALLAI, Helena Copetti. A licenciatura de geografia e a articulação com a educação básica. In: CASTROGIOVANNI, Antonio Carlos et al. Geografia em sala de aula: práticas e reflexões. 3. ed. Porto Alegre: Editora da Universidade/UFRGS/Associação dos Geógrafos Brasileiros - Seção Porto Alegre, 2001.

AZZI, Roberta Gurgel; SADALLA, Ana Maria Falcão de Aragão (Orgs.). Psicologia e formação docente: desafios e conversas. São Paulo: Casa do Psicólogo, 2002.

BARDIN, Laurence. Análise de conteúdo. Lisboa: Edições 70, 1977.

BRABANT, Jean-Michel. Crise da geografia, crise da escola. In: OLIVEIRA, Ariovaldo Umbelino de (Org.). Para onde vai o ensino de geografia? 7. ed. São Paulo: Contexto, 2001.

BRASIL. Ministério da Educação. LDB. Lei 9394/96 - Lei de Diretrizes e Bases da Educação Nacional. 1996. Disponível em: <http://portal.mec.gov.br/arquivos/ pdf/ldb.pdf >. Acesso em: 21 fev. 2015.

Secretaria de Educação Fundamental. Parâmetros curriculares nacionais: terceiro e quarto ciclos do ensino fundamental (Introdução). Secretaria de Educação Fundamental - Brasília: MEC/SEF, 1998.

CRUZ, Marília Beatriz Azevedo. O ensino de história no contexto das transições paradigmáticas da história e da educação. In: NIKITIUK, Sônia Maria Leite (Org). Repensando o ensino de história. 2. ed. São Paulo: Cortez, 1999.

CUNHA, Maria Isabel da. 0 bom professor e sua prática. 17. ed. Campinas: Papirus, 2005.

FAZENDA, Ivani Catarina Arantes. (Org.). 0 que é interdisciplinaridade. São Paulo: Cortez, 2008.

FONSECA, Selva Guimarães. Didática e prática de ensino de história. 7. ed. Campinas: Papirus, 2008.

FONSECA, Thais Nivia de Lima e. História e ensino de história. 2. ed. Belo Horizonte: Autêntica, 2006. 
GATTI, Bernadete Angelina; GARCIA, Walter E. Bernadete Gatti - educadora e pesquisadora: textos selecionados. Belo Horizonte: Autêntica, 2011.

KOCHHANN, Andréa; AFONSO, Leidijane. Ensinar história ou construir história: uma consciência teórico-metodológica da práxis docente. Universidade Estadual de Goiás, São Luís de Montes Belos. Pedagogia, disciplina de Conteúdos e Processos do Ensino de História, 2009. Disponível em: 〈http://www.slmb.ueg.br/paidos/ artigos/1_ensinar_historia_ou_construir_historia.pdf〉. Acesso em: 13 fev. 2015.

LEITE, Sérgio Antônio da Silva (Org.). Afetividade e práticas pedagógicas. São Paulo: Casa do Psicólogo, 2006.

MARTINEZ, Albertina Mitjáns; SCOZ, Beatriz Judith Lima; CASTANHO, Marisa Irene Siqueira (Orgs.). Ensino e aprendizagem: a subjetividade em foco. Brasília: Liber Livro, 2012.

MENEZES, Ebenezer Takuno de; SANTOS, Thais Helena dos. Licenciatura curta (verbete). Dicionário interativo da educação brasileira - EducaBrasil. São Paulo: Midiamix Editora, 2002.

OLIVEIRA, Ariovaldo Umbelino de. Situação e tendências da geografia. In:

(Org.). Para onde vai o ensino de geografia? 7. ed. São Paulo: Contexto, 2001. p. 24-29.

PALMA FILHO, João Cardoso. A política nacional de formação de professores. In: BARBOSA, R. L. L. (Org.). Trajetórias e perspectivas da formação de educadores. São Paulo: Unespi, 2004. p. 145-167.

PEREIRA, Júlio Emílio Diniz. Formação de professores e poder. 2. ed. Belo Horizonte: Autêntica, 2006.

PONTUSCHKA, Nídia Nacib; PAGANELLI, Tomoko Iyda; CACETE, Núria Hanglei. Para ensinar e aprender geografia. São Paulo: Cortez, 2007.

RATIER, Rodrigo Pelegrini; SALLA, Fernanda. Ser professor: uma escolha de poucos (reportagem). Nova Escola, 1ํ dez. 2010. Disponível em: < http://revistaescola. abril.com.br >. Acesso em: 21 fev 2015.

RICHARDSON, Roberto Jarry; PERES, José Augusto de Souza; CORREIA, Lindoya Martins; PERES, Maria de Holanda de Melo; WANDERLEY, José Carlos Vieira. Pesquisa social: métodos e técnicas. São Paulo: Atlas, 1989.

ROCHA, Genylton Odilon Rêgo da. Uma breve história da formação do(a) professor(a) de geografia no Brasil. Terra Livre, São Paulo, n. 15, p. 129-144, 2000.

SAMPAIO, Adriany de Ávila Melo; VLACH, Vânia Rúbia Farias; SAMPAIO, Antônio Carlos Freire. História da geografia escolar brasileira: continuando a discussão. In: CONGRESSO LUSO-BRASILEIRO DE HISTÓRIA DA EDUCAÇÃO, 6., 2006, Uberlândia. 
Anais... Uberlândia: Universidade Federal de Uberlândia, 2006. Disponível em: 〈http://www2.faced.ufu.br/colubhe06/anais/arquivos/239AdrianyMelo_ VaniaRubia.pdf 〉. Acesso em: 21 fev 2015.

SAVIANI, Dermeval. Educação: do senso comum a consciência filosófica. 11. ed. Campinas: Editora Autores Associados, 1996. (Educação contemporânea).

Formação de professores: aspectos históricos e teóricos do problema no contexto brasileiro. Revista Brasileira de Educação, Rio de Janeiro, v. 14, n. 40, p. 143-155, 2009.

SCHMIDT, Maria Auxiliadora; CAINELLI, Marlene. Ensinar história. São Paulo: Scipione, 2004 (Pensamento e ação no magistério).

SILVA, Francisco das Chagas Rodrigues da. Formação do professor de geografia no Brasil: configurações político-institucionais e repercussões no ensino. In: SEMINÁRIO INTERNACIONAL RED ESTRADO, 8., 2010, Lima. Anais... Lima: UCH/ CLACSO, 2010, v. único.

SISTO, Fermino Fernandes; OLIVEIRA, Gislene de Campos; FINI, Lucila Dihel Tolaine (Orgs.). Leituras de psicologia para formação de professores. 2. ed. Petrópolis: Vozes; Bragança Paulista: Universidade São Francisco, 2000.

TADIOTTO, Luciana Bedin; BOGADO, Samir Recalde; SPANCESKI, Janice Licieski. 0 ensino de geografia e o aprendizado na escola. Instituto de Ensino Superior (ISE)- Faculdade de Ensino Superior de São Miguel do Iguaçu (UniguaçuFaesi). Licenciatura em Geografia, disciplina de Estágio Supervisionado na Regência, 2010. Disponível em: 〈http://www.faesi.com.br/nucleo-de-pesquisacientifica/75-portal-do-saber/220-o-ensino-de-geografia-e-o-aprendizado-naescolà. Acesso em: 13 fev 2015.

VESENTINI, José William. A formação do professor de geografia: algumas reflexões. In: PONTUSCHKA, Nídia Nacib; OLIVEIRA, Ariovaldo Umbelino de (Orgs.). Geografia em perspectiva. 3. ed. São Paulo: Contexto, 2006. p. 234-234.

VILLELA, Tereza Cristina Rodrigues; GUERREIRO, Elaine Maria Bessa Rebello; LOPES, Silvia Carla. Os desafios da inclusão escolar no século XXI. In: ENCONTRO IBEROAMERICANO DE EDUCAÇÃO, 6., 2011, Araraquara. Anais... Araraquara: UNESP campus de Araraquara, 2011.

RECEBIDO: Fevereiro de 2015.

APROVADO: Abril de 2015 